\title{
o método cooperação dos Amigos do cinema
}

\author{
LARA LIMA SATLER \\ ALICE FÁTIMA MARTINS
}

\section{Resumo}

Neste texto, pretendemos discutir como o Sistema

CooperAÇÃO - Amigos do Cinema se articula em coletivo e simultaneamente realiza suas produções audiovisuais. $\mathrm{O}$ Sistema CooperAÇÃO é formado por um grupo de amigos que há mais de quatorze anos já produziu um total de quinze filmes no interior do Brasil, no Estado de Goiás. Os dados aqui apresentados foram coletados por meio de observação direta e entrevistas. Objetivamos compreender como o grupo se articula em coletivo e como realiza seus filmes. Como resultados, pretendemos contribuir com discussões que problematizem as relações entre o realizar filmes em coletivos.

Palavras-chave:

Realizar filmes, coletivos, cooperação 


\title{
The cooperation method of the Amigos do Cinema
}

\author{
LARA LIMA SATLER \\ ALICE FÁTIMA MARTINS
}

\section{Abstract}

In this paper, we intend to discuss how the Sistema CooperAÇÃO - Amigos do Cinema is articulated collectively and simultaneously performs its movies productions. The Sistema CooperAÇÃO is formed by a group of friends for over fourteen years has produced a total of fifteen films in the interior of Brazil, in the State of Goiás. The data presented were collected through direct observation and interviews. We aim to understand how the group is

Keywords: Filmmaking, collectives, cooperation articulated collectively and how make their movies. As a result, we intend to contribute with discussions that think about the relationship between making films in collectives. 


\section{Apresentação}

Neste texto, pretendemos discutir como o Sistema CooperAÇÃO - Amigos do Cinema se articula em um coletivo artístico e desse modo realiza suas produções audiovisuais. O Sistema CooperAÇÃO se apresenta como "um grupo de amigos que produzem [de modo] independente. Técnicos e atores unidos com um só objetivo, estudar cinema" (encarte dos DVDs).

O grupo já lançou quinze produções, entre filmes de curta, média e longas metragem ${ }^{1}$. Acompanhamos as filmagens da produção intitulada O Capitão do Mato (MARTINS MUNIZ, 2013), entre fevereiro e março de 2013, em locações que incluíram Goiânia, Aparecida de Goiânia e Cedro, um povoado próximo a Trindade, todos no estado de Goiás. Assim, interessa-nos compreender, nesta reflexão: como a organização do grupo se articula em coletivo? Como o grupo articula seu duplo objetivo de realizar filmes e fazê-los em cooperação? Para tanto, investigaremos as implicações que o fazer filmes em coletivo exercem na produção audiovisual deste grupo.

Este texto é fruto de duas pesquisas em andamento, uma intitulada "Outros fazedores de cinema", e a outra "Eu, a câmera e o outro: aprender a realizar audiovisual experimentando em coletivo", ambas com seus projetos financiados pela Fundação de Amparo à Pesquisa do Estado de Goiás - FAPEG. Os dados aqui apresentados foram coletados por meio de observação direta e entrevistas. Objetivamos, com esta reflexão, compreender como o Sistema CooperAÇÃO - Amigos do Cinema se articula em coletivo e como realiza seus filmes em cooperação. Como resultados, pretendemos contribuir com discussões que problematizem as relações entre o realizar filmes em coletivos. 


\section{O sentido de coletivo artístico na contemporaneidade}

Segundo Paim (2012, p.7), coletivos são

Agrupamentos de artistas ou multidisciplinares que, sob um mesmo nome, atuam propositalmente de forma conjunta, criativa, autoconsciente e não hierárquica. O processo de criação pode ser inteira ou parcialmente compartilhado e buscam a realização e visibilidade de seus projetos e proposições. Os coletivos podem ser mais ou menos fechados. Alguns possuem uma formação fixa e determinada internamente, outros, um núcleo central em torno do qual se agregam distintos parceiros de acordo com os projetos em execução.

A autora propõe uma categorização distinguindo coletivo de iniciativas coletivas, que define por "projetos com autogestão de equipes de trabalho constituídas por artistas ou mistas, que se formam para um determinado fim e que não pretendem estabelecer vínculos como nos coletivos nem tem o propósito de formar um coletivo" (idem, p. 8). De acordo com esta distinção os coletivos tem uma formação fixa e, simultaneamente, móvel, isto é, possuem um núcleo fixo e parceiros que são mobilizados a partir de determinados projetos. Já as iniciativas coletivas são sempre móveis e de articulação efêmera.

Mesquita (2008), que investiga uma produção coletiva com enfoque em arte ativista, coletiva e intervencionista, aprofunda a discussão ao argumentar que o coletivismo com este enfoque artístico inicia-se na metade do século XIX. Posteriormente, pode ser observado nas vanguardas artísticas européias, em manifestações do pós-guerra, de teatro de rua, de grupos militantes e vivências engajadas da Arte Conceitual de 1960 e 1970, bem como o ativismo cultural voltado à comunidade e aos movimentos sociais europeus, norte-americanos, argentinos e brasileiros. O autor relata a impossibilidade de listar em sua completude, mas observa que o coletivismo artístico do pós-guerra é expressivo também no Japão, Leste Europeu, México, Cuba, África do Sul, Oriente Médio e Rússia.

A pesquisa de ambos os autores acima dialogam, direta ou indiretamente, com Collectism After Modernism: The Art of Social Imagination After 1945 cujos organizadores Stimson e Sholette (2007) afirmam ser um livro que abre as portas do estudo sobre coletivismo artístico, compreendendo-o não como representação de uma prática artística genial, mas com o intuito 
de teorizá-lo como uma forma de produção e intervenção que promove questões sobre a natureza do trabalho criativo e como a história é contada, por quem e com quais finalidades. Esta obra, em que seus capítulos são assinados por diversos autores, pretende trazer a discussão a partir dos efeitos da mudança de ponto de vista sobre o coletivismo. E mesmo que seu foco seja contemporâneo, os organizadores buscaram reconhecer algumas distinções entre agrupamentos artísticos pré e pós-guerras mundiais. Assim, Stimson e Sholette (2007, p.10) ${ }^{2}$ apresentam que a "coletivização da produção artística não é novidade", mas ela "é uma ocorrência que parece não ter vida ideológica após o período pós-guerra, não ter ismos para se sustentar como um empreendimento vivo, não ter literatura crítica para lhe dar orgulho de ter um lugar na história". Em contrapartida, afirmam que o moderno coletivismo artístico anterior ao pós-guerra estava vinculado ao comunismo como um ideal, que ao falhar teria deixado poucas escolhas a não ser distanciar-se de grandes ismos. Seria ingênuo, acrescentam, pensar que o coletivismo atrelado a grandes ideais sucumbiu, contudo, a obra busca refletir sobre as redefinições que coletivos artísticos buscaram em termos de significados, propósitos, formas de vitalidade política que tenham impacto em sua própria concepção de arte, tendo em vista este passado.

Os organizadores apóiam este argumento em características de agrupamentos, que além dos já listados acima por Paim e Mesquita, citam os futuristas, surrealistas, produtivistas, muralistas, realistas sociais e outras ocorrências entre 1950 e 6o como o expressionismo abstrato, os happenings, a pop art, o minimalismo e outras categorias artísticas que se compuseram em coletivo. Mas argumentam que nenhuma delas defendeu a bandeira coletiva, nem tinham a coletivização como vital ou primária para a sua arte, nem mesmo exploraram a afiliação ao grupo como medida da sua autonomia artística.

Stimson e Sholette (idem) argumentam, portanto, que o coletivismo artístico pode e deve ser estudado em seus períodos distintos ao longo da história, pois podemos ganhar em precisão e definição se assim o fizermos. Ainda esclarecem que nós estamos em uma posição diferenciada para olhar as novas oportunidades que emergem dos coletivismos contemporâneos. Citam, por exemplo, o trabalho do coletivo Temporary Services, de Chicago, cujas imagens (figuras 1, 2 e 3) sugerem uma provocação ao fenômeno público do descarte, por isso, o título da compilação é Public Phenomena. No Flickr do grupo, ela está legendada como "Fenômeno 


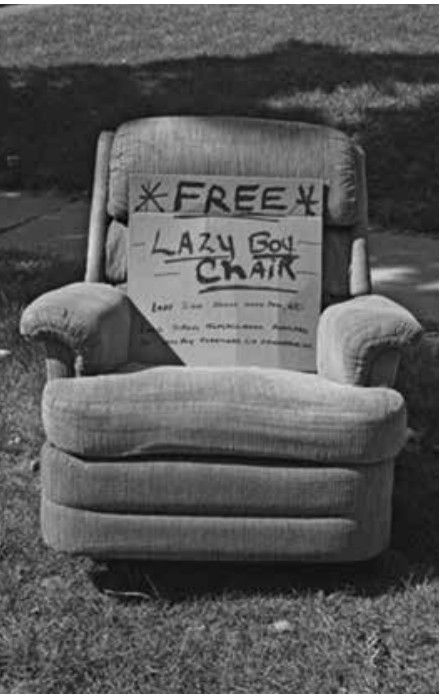

Figura 1

Free 1 for Public Phenomena. Cortesia de Temporary Services.

Figura 2

Free_2 for Public Phenomena. Cortesia de Temporary Services.

Figura 3

Free_8 for Public Phenomena. Cortesia de Temporary Services.
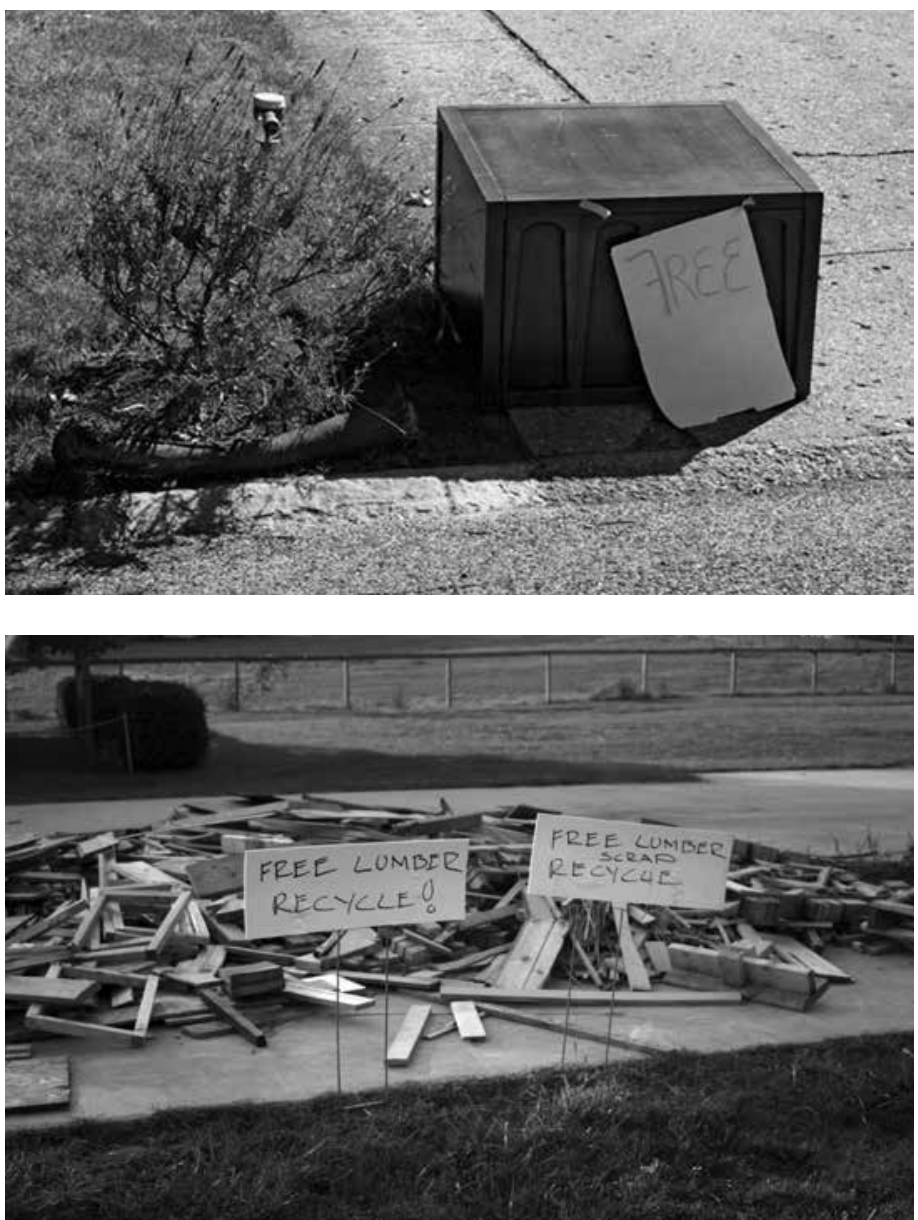

Público - Objetos GRATUITOS deixados no lado da calçada em Urbana, Illionis"3 (grifos do autor). A proposta destas imagens está em um booklet, uma espécie de livro-panfleto, disponibilizado no site do grupo, cujo título é Fenômeno Público - Modificações Informais dos Espaços Compartilhados e produzem sentido pela sua reunião em torno do objetivo descrito como "Desde a origem do Temporary Services em 1998, nós assumimos o ativo interesse na cultura vernácula encontrada publicamente no espaço transitável"4. O sentido de cultura vernácula se revela pela singularidade das intervenções expressas nos espaços por aqueles que os usam, as quais são captadas em imagens por um grupo que despretensiosamente transita nestes espaços, à deriva. 
Retomando o argumento de Stimson e Sholette (idem), diferentemente dos modernistas, o texto do booklet apresenta que a compilação e sua concepção são do coletivo como se todas as etapas da construção artística fossem de todos os três membros do grupo, que são responsabilizados sem distinção de autoria. Além disso, a própria intervenção não é obra do coletivo, é antes do público, que ao se expressar publicamente interfere nos espaços em que transita, de modo que o coletivo observa, registra e dialoga visualmente com ele, sem deixar claro quem é responsável pelas imagens, pela ideia da compilação, pelo booklet ou mesmo pelo sítio onde estão. Por isso, parece-nos que além de se afirmarem enquanto coletivo, há nestes agrupamentos atuais a opção por não individualizar, expressa na temática da obra - a intervenção de um coletivo maior, chamado de público, nos seus espaços de trânsito - e também na recusa de uma autoria individual por quem poetiza tal intervenção.

A pesquisa de Paim (2009) tem como foco modos de fazer coletivo e iniciativas coletivas artísticas como posição política, observadas a partir de 1990, em alguns países da América do Sul. Assim apresenta que espaços artísticos autogestionados recebem impulso neste contexto devido à retração de mercado de artes praticado solitariamente e destinado às galerias; ao fim das ditaduras militares na América Latina e aos nascentes movimentos de redemocratização que possibilitam microassociações; a crise econômica de países latino-americanos promove o sucateamento de incentivos estatais à cultura; o aumento de cursos de artes fomenta a convivência e a crítica da atuação; a popularização dos meios de comunicação em rede, bem como a globalização dos mercados e flexibilidade do trabalho.

Já Hollanda (2013) formula outra compreensão dos coletivos na atualidade. Para a autora a atuação dos coletivos de artistas plásticos apresenta-se como um segmento surpreendente no campo da produção cultural contemporânea. Argumenta que surgem no final dos anos 1990 e tem como foco de intervenção no espaço urbano. Sobre este fenômeno, Hollanda (2013) afirma

Os coletivos, que se propagam em proporção geométrica pelo Brasil, trazem um plus de novidade. Os coletivos não se configuram por seus integrantes e sim por determinadas ações, agindo sempre num contexto de intervenção pública. Os coletivos também não são cooperativas, não são grupos, não tem número de participantes determinado, nem podem 
ser caracterizados como movimentos artísticos. Sua forma de organização é independente e, para cada ação ou conjunto de ações, os coletivos buscam patrocínio, oferecendo cursos, vendendo trabalhos ou realizando serviços como ilustração, design, vídeo etc. Esta auto-gestão elimina, portanto, a figura do curador, personagem cujo poder seletivo e decisório cresceram muito nos últimos 20 anos, adquirindo uma função de autoridade centralizadora no sistema das artes.

A autora tem como referência o modo de se organizar de grupos e cooperativas de 1970 quando afirma que os coletivos contemporâneos se diferenciam deles por serem "estruturalmente nômades", por se unirem "apenas em função de projetos tópicos" e por se caracterizarem "pela reunião em torno de ações concretas e imediatas, rejeitando a idéia de projetos a longo e médio prazos". Ou seja, quando a autora nega a nomeação de grupo ou de cooperativa aos coletivos dos dias atuais está considerando a mobilidade e a agilidade em que seus membros se organizam em torno de projetos curtos ou ações pontuais. Por exemplo, hoje um artista participa de um projeto em um coletivo X e amanhã pode participar em um coletivo $Y$ e posteriormente ainda voltar a se envolver com outros projetos no coletivo X. Esta flexibilidade das relações entre os membros dos coletivos é que leva a autora a diferenciar os coletivos de hoje de grupos e cooperativas.

Desse modo, ela os caracteriza não pelos membros do grupo, mas pelas suas ações. São estas ações que geram, em sua opinião, a organização de um coletivo na atualidade. Por isso, ela qualifica a organização deles como rizomática e nômade. Além de uma comunicação intensa por meio de sites de serviço de redes sociais e $b l o g s$, que podem ser utilizados como espaços de troca de informação, interação e produção de conhecimento, retomando o argumento de Hollanda (2013), os coletivos artísticos contemporâneos caracterizam-se ainda pela autogestão, descentralização, flexibilidade das relações, articulação situacional e por agirem intervindo no espaço público.

Nem apenas móvel, nem apenas fixo, Mesquita (2008, p. 22) argumenta que desde os anos de 1990 no Brasil os coletivos artísticos tem se organizado de diversos modos e a partir de distintos objetivos, por isso, afirma "temos a existência de alguns coletivos trabalhando em conjunto há mais de dez anos, assim como agrupamentos efêmeros e temporários".

Sobre os modos de organização coletiva, o autor comenta que os grupos atuais optam por formações descentralizadas e heterogêneas a partir de três vetores: autoria do projeto, proces- 
sos de organização e criação da obra. Neste sentido, argumenta que a pesquisa empírica sobre a organização social torna-se tão importante para tais artistas quanto à tradicional pesquisa sobre os materiais e produtos. Mesquita (2008, p. 51) observa que,

Vemos artistas trabalhando coletivamente a partir de uma única proposta ou em colaboração com indivíduos de diferentes áreas. Há também artistas que se reúnem em torno de uma ideia coletiva ou de um movimento, mas desenvolvem suas obras individualmente, assim como um projeto artístico com a participação do público, de uma comunidade ou de um grupo político.

Desse modo, exemplifica sobre alguns modelos de práticas coletivas. Em coletivos cujos membros mantem-se fixos por um tempo, segundo o autor, a autoria expressa o modo do grupo se organizar e conviver, seu modus vivendi enquanto grupo. Em outros casos, projetos criados por um único artista buscam a colaboração, a participação e negociação de indivíduos, baseando-se em situações sociais, de modo que o artista agencia a percepção social e crítica junto a comunidades e grupos, chamando-os a co-produzir e co-criar. Nesta direção, o diálogo, a interação, o encontro e a convivência são interesse da sua arte. Há ainda artistas que buscam a transversalidade, em oposição a uma verticalidade do hierárquico ou piramidal e também além de uma horizontalidade. Neste sentido buscam-se diversos níveis, disciplinas, grupos, movimentos e atores, assim, desafiam-se as noções de autoria, o culto ao artista, optando pelo anonimato do artista por meio do uso de pseudônimos ou adoção de nomes múltiplos, os quais podem ser usados por qualquer pessoa em uma ação. Trata ainda de coletivos com filiações flexíveis e temporárias voltados para projetos de intervenção social e artística, chamando-as de coalizões temporárias.

Paim (2009, p. 27) acrescenta à discussão outros traços nos modos de fazer de coletivos da atualidade, observando que nem todos eles são notados constantemente,

- fazeres que não obedeça às decisões tomadas por um núcleo fechado; são descentralizados e compositivos de muitas falas;

- não-hierarquizados;

- podem ter mobilidade;

- são emancipatórios e positivos - propõe a saída da rigidez das ideias prontas e revelam o que elas tem de construção ideológica; - utilizam a auto-organização e são autogestionados e também são modos de fazer desburocratizados e ágeis; 
- apresentam tendência a operar com noções de site-specific ou oriented-site;

- contam com autoria coletiva em, pelo menos, alguma etapa dos projetos;

- usam o ciberespaço (como espaço da prática ou como meio para sua organização e difusão);

- podem ser organizados por coletivos de artistas ou com formação heterogênea.

A autora, cuja pesquisa com coletivos artísticos se afina com o enfoque em arte e ativismo político, apresenta com outras palavras características acima discutidas. A característica da emancipação, citada por ela, decorre da desconstrução de modos de fazer ideologicamente consagrados, mas também sugere uma valorização do fazer e, consequentemente, uma contínua reflexão sobre este processo. Sennett (2012, p.18) reflete que o fazer é um modo de pensar e um modo de aprender sobre nós mesmos, por isso, argumenta que "as pessoas podem aprender sobre si mesmas através das coisas que fazem”. Compreendemos ser este o sentido da característica emancipatória dos coletivos para a autora, da sua possibilidade de construir e desconstruir aprendizagens sobre si mesmo em grupo.

Já a tendência a operar com noções de site-specific ou oriented-site remete à noção de arte pública que, por sua vez, expressa a ideia de uma arte realizada fora dos espaços consagrados a ela, como galerias, museus, salas de projeção etc. De acordo com a Enciclopédia Itaú Cultural de Artes Visuais (2010), obras ou instalações operando com tais noções podem modificar os ambientes, corriqueiramente espaços públicos e urbanos, embora também vistas em ambientes naturais, de modo permanente ou temporário. Assim, tanto site-specific quanto sítio específico

Faz menção a obras criadas de acordo com o ambiente e com um espaço determinado. Trata-se, em geral, de trabalhos planejados - muitas vezes fruto de convites - em local certo, em que os elementos esculturais dialogam com o meio circundante, para o qual a obra é elaborada. Nesse sentido, a noção de site specific liga-se à ideia de arte ambiente, que sinaliza uma tendência da produção contemporânea de se voltar para o espaço - incorporando-o à obra e/ou transformando-o -, seja ele o espaço da galeria, o ambiente natural ou áreas urbanas. Relaciona-se de perto à chamada land art [arte da terra], que 
inaugura uma relação com o ambiente natural. Não mais paisagem a ser representada, nem manancial de forças passível de expressão plástica, a natureza é o locus onde a arte se enraíza.

Focando apenas em coletivos que agem artisticamente a partir de um projeto imediato e concreto, Hollanda (2013) argumenta que o coletivo se estrutura e recompõe com outros membros para ações seguintes, consequentemente, estruturando outro coletivo. Portanto, tal organização estruturada em função de cada uma de suas ações requer como suporte uma comunicação intensa entre coletivos por meios blogs e listas de discussão na internet, que para Hollanda (2013), "alguns sites reúnem as informações de forma mais nodal, explicitando melhor a lógica de rede que rege essa produção". Por exemplo, em São Paulo, o coletivo Horizonte Nômade iniciou uma articulação de artistas que trabalhavam em coletivos brasileiros a partir de um levantamento destes realizado por Flávia Vivacqua, em 2000. Desta articulação surgiu em 2002 o CORO - Colaboradores em Redes e Organizações, com objetivo de "unir outros artistas que também trabalhavam coletivamente no Brasil"s.

Vimos que embora tenhamos a surpreendente atuação artística destes agrupamentos de 1990 aos dias atuais, no Brasil, eles nem são tão novos, tampouco trazem modos de fazer, de se organizar, bem como motivações originais. Todavia, a relação entre arte e coletivo, seja com ênfase no ativismo político, seja no encontro afetivo, seja no profissional, ou mesmo com elas conjugadas, este fenômeno precisa ser observado, compreendido e avaliado, pois tem se mostrado um fenômeno fértil tanto na construção de espaços comum, quanto na reflexão sobre modos de fazer filmes em grupo, o que estudaremos melhor no próximo item.

\section{O método CooperAÇÃO dos Amigos do Cinema}

Embora não exista formalmente, o Sistema CooperAÇÃO - Amigos do Cinema iniciou suas atividades em 1999, primeiro ano da realização do Festival Internacional de Cinema e Vídeo Ambiental (FICA), na Cidade de Goiás, Estado de Goiás. Na ocasião, Martins Muniz tinha uma produtora de filmes e alguns amigos o convidaram a realizar uma produção cinematográfica para inscrevê-la no festival e sua resposta foi "se vocês ajudarem, nós fazemos o filme [...] ajuda com trabalho" (MUNIZ, 2013a). 
Segundo ele, desde esta época o grupo mantem em suas realizações a proposta de "ajuda com trabalho", que pode ser traduzida pela cooperação por meio de trabalho voluntário com opiniões, participação e experimentações em conjunto, em coletivo. No trecho abaixo, Muniz (2013b) relata que o Sistema CooperAÇÃO surge de um sonho com o cinema de longa data

Eu, desde o início, desde criança, tinha vontade de fazer cinema, mas não tinha como, de família pobre não tinha condições nenhuma de fazer filme, era inviável. A única [opção] que tinha na minha época era a película. Aí eu fiquei sonhando com essa história toda a vida. Aí achei que deveria ser operador de cinema para projetar filme, para poder ficar mais perto da película, para poder manusear a película, né? Aí fui ser operador de cinema. Entrei no Cine Campinas, na época áurea do cinema. Cine Capri fui eu que inaugurei operando filme de 70 milímetros, Cine Ouro foi que inaugurei também projetando filmes e ninguém sabe disso, e aí fui aprendendo. Aí cansei de... [operar]. Aí estudei fotografia, estudei pintura, estudei desenho, fui estudando tudo o que no cinema precisava eu ia aprendendo, lutando para aperfeiçoar, aprender mais. Teve uma época em que eu fazia os cartazes do cinema, pintava as telonas grandes do cinema, você não lembra isso, você é menina, não tinha o plotter, era feito à mão, para frente do cinema...

- Com cartazes colados?

- Não, pintura. Fazia painel para frente do cinema, inteiriço. 5 metros por 10 metros de tamanho.

- Você fazia?

- Fazia, era o Ti Érikes e eu. Aí eu queria aprender mais e eu não tinha como, e aí eu soube da Makro Filmes, a Makro Filmes do Euclides Néry, você conhece, né? O pioneiro do cinema de Goiás. Aí eu entrei lá e falei “vou trabalhar com vocês aqui”, e eles "mas não temos dinheiro, não tem como te contratar", e eu "mas eu trabalho de graça, desde que você me deixa meio período para eu trabalhar fora". Aí comecei a trabalhar com eles, aí fui entrando com eles e rapidinho eu consegui um salário lá dentro, porque eu sabia fotografar, sabia fazer fotolito, sabia desenhar, eles estavam fazendo um desenho animado para um leite... Aí eu comecei a colorir o acetato do filme deles e comecei aprender vagarosamente. Aí eu cheguei a alcançar um bom salário de Goiás. Aí fiquei empregado toda vida, empregado não tem valor, é máquina, é complemento da mão do patrão, aí fui batalhar por outros lados, mas quando eu saí da Makro 
eu já sabia filmar, já manuseava o equipamento deles, aí estava pronto para trabalhar. Aí comecei a trabalhar independente. Agora o sonho do cinema grande, eu queria saber fazer cinema grande, porque eu entrei na publicidade querendo fazer aprender fazer cinema grande.

- O que é cinema grande?

- Mais de duas horas, uma hora de projeção. Porque o comercial é trinta segundos. Estourando trinta segundos, tem que contar uma historinha em trinta segundos, então é difícil satisfazer a gente. No cinema longo a gente faz a cena, só uma cena dá 15 minutos se precisar, né? Igual nessa gravação que você está fazendo; a gravação vai dar mais de 15 minutos, não é? Aí eu sonhava com cinema, procurava onde tinha uma filmagem de um longa metragem eu aproximava, mas as cabeças dos filmes já vinham tudo feito pelo diretor de fora. Eles não davam chance para as pessoas de Goiás. Como nunca deu. Quando tem uma filmagem igual essa novela que apareceu [Em família, exibida em 2014], essa gracinha aí, pega os melhores atores nossos como figurantes e olha lá se eles aparecem, é muito difícil aparecer. Aí eu sonhava com o cinema. Aí chegou um ponto recentemente, há 10 ou 12 anos atrás, eu soube que tinham muitas pessoas que tinham esse mesmo sonho do cinema e não tinha como fazer aí falou: "por que você não faz um filme para nós atuar?" (sic.), aí eu falei, "vamos fazer o seguinte, eu entro com a câmera e o material e vocês entram com a mão de obra de vocês", aí fizemo uma união e criamos um sistema de cooperativa, CooperAÇÃO. Aí o ator atuava, a atriz atuava, a figurinista fazia o figurino e todo mundo uniu e fez o primeiro filme que foi "A lenda do milho", aí deu certo, aí fizemos "O Matuto" e foi fazendo filmes aí e o grupo cresceu. Hoje quando eu vou falar vou fazer um filme eu tenho que selecionar os caras e faço até inimizade porque todo mundo quer ir, mas não tem espaço para todo mundo e eles vai (sic.) pela farra, aí todo mundo trabalha no sentido de fazer uma produção independente. Aí nós pega (sic.) esse filme feito, cada um fica com uma cópia e mostra em tudo quanto é espaço, mostra para um e para outro e faz as sessões particulares e vamo (sic.) distribuindo. Esse é o sonho do cinema nosso, do Sistema CooperAÇÃO. E pretendemos fazer muito mais.

Notamos que a motivação para o Sistema CooperAÇÃO Amigos do Cinema se constituir como agrupamento emerge da combinação de um grande sonho do seu articulador, o Martins 
Muniz, e de amigos e atores de teatro e cinema em Goiás em reação aos preconceitos que são de ordem lingüística, mas também estética, social, econômica e até de sotaque em relação às realizações fílmicas do interior do Brasil. A motivação expressa ainda críticas ao modo provinciano de conceber os festivais regionais e ao relacionamento ainda hierárquico e desigual que emissoras nacionais estabelecem com atores locais.

Desse modo, argumentamos que a formação do Sistema CooperAÇÃO se dá pela via da produção independente assim como muitos outros grupos artísticos optam por ela. O que implica em percebermos que a existência deste grupo faz eco com muitos coletivos artísticos contemporâneos, mesmo que ele tenha optado por se denominar cooperativa, um termo que expressa uma referência organizacional distinta dos agrupamentos atuais, como discutido acima por Hollanda (2013).

Além disso, compreendemos que embora o CooperAÇÃO não faça uso do termo coletivo, utilizado como sinônimo de agrupamento urbano atual, sua formação se dá por projeto, ou seja, como Muniz apresenta acima, a cada novo filme, um grupo distinto se configura, de modo a trabalhar como grupo apenas durante o desenvolvimento do filme. Avançando um pouco mais nesta perspectiva e considerando a experiência das filmagens de O Capitão do Mato (MARTINS MUNIZ, 2013), que foi uma das poucas captações fragmentadas em finais de semana ao longo de dois meses, argumentamos que a cada final de semana um novo agrupamento se formava, tornando o projeto um desafio ao continuísmo, à capacidade de improvisação do grupo e à coerência narrativa.

Este dado é certamente um dos mais importantes de se considerar ao assistirmos os filmes do Sistema CooperAÇÃO; uma vez que o grupo filma nos finais de semana, pois segundo Muniz (2013b) não há remuneração para a equipe envolvida, vivencia imprevistos de diversas naturezas.

Era 7 h23 e dois dos atores principais não tinham chegado e não atendiam ao celular. Tínhamos marcado para sair às $7 \mathrm{~h}$. Na porta da casa do Muniz, local de encontro para saída em direção à locação daquele domingo, Muniz me pergunta: "São três pretos fujões na nossa história, se eu deixar só um, a história fica ruim?" (SATLER, Diário de campo, em 24 de fevereiro de 2013).

Desse modo, as circunstâncias geradas pela efemeridade do agrupamento do Sistema CooperAÇÃO requisitam uma 
capacidade de ir e vir na narrativa fílmica das suas realizações, o que se traduz por uma flexibilidade na coerência e no continuísmo, bem como na necessidade de refazer o filme continuamente. É como se o roteirista e diretor, que é também o articulador do grupo, tivesse o filme na memória, mas devido às necessidades e imprevistos substituísse partes, adicionasse camadas, recortasse trechos e assim procedesse mentalmente durante todo o processo de captações que envolvem o coletivo.

Contudo, não é apenas isso que parece acontecer. No caso específico de O Capitão do Mato (MARTINS MUNIZ, 2013), todo esse processo de ruminação mental da realização fílmica acontece entremeado de diálogos constantes com quem está no set de filmagem, seja este ator, equipe técnica ou diletante do grupo.

Depois de gravadas as cenas, ele as assiste e confere se ficaram boas. Todos assistem numa tela de quatorze polegadas e comentam. [...] O Fábio, o Eurípedes e o Muniz comentam entre si e perguntam uns aos outros se as cenas assistidas estão boas ou precisam regravação. Também os participantes comentam, interferem, criticam, elogiam (SATLER, Diário de campo, em 17 de fevereiro de 2013).

Deste método de fazer e refazer continuamente, estimulando como os presentes observam o que foi filmado e se merece ser refilmado é argumentamos que o sentido de CooperAÇÃO no nome deste grupo se afina mais com o conceito de cooperação do quem com a ideia de cooperativa discutida acima por Hollanda (2013). Assim, para compreender sobre o método dos Amigos do Cinema e sua articulação em coletivo dialogamos com o conceito de cooperação de Piaget (1973, p.64), que a define como "um sistema de operações executadas em comum ou por reciprocidade entre as [regras racionais] de seus parceiros".

Para a Piaget (1998, p. 118, grifos do autor), a cooperação é um processo "constituído pela ação dos indivíduos uns sobre os outros quando a igualdade (de fato e de direito) suplanta a autoridade", por isso "a coerção desaparece dando lugar à cooperação, e o respeito torna-se mútuo". Neste sentido Piaget (idem, ibidem) acrescenta

Embora a cooperação nunca se desvencilhe completamente de toda coerção e embora o respeito não possa chegar a uma total reciprocidade, o segundo processo [o da cooperação] define um ideal cujos efeitos são qualitativamente diferentes 
dos da coerção. Enquanto que esta última tem por resultado essencial impor regras e verdades já elaboradas, a cooperação (ou as tentativas de cooperação) provoca, ao contrário, a constituição de um método que permite ao espírito superar a si mesmo incessantemente e situar as normas acima dos estados de fato. Do ponto de vista moral, a cooperação leva não mais à simples obediência às regras impostas, sejam elas quais forem, mas a uma ética da solidariedade e da reciprocidade.

Durante as gravações, observamos que a relações de hierarquia, presentes em certos modos de produção cinematográfica tradicional, são organizados dentro do próprio grupo, representando o que Piaget mencionou acima por regras autônomas de conduta, fundamentadas no respeito mútuo. Assim, observamos que a hierarquia representa o nível de responsabilidade do membro do grupo, em detrimento de uma figura de autoridade irrevogável ou inacessível.

Muniz foi definido pelos membros do Sistema CooperAÇÃO como o diretor dos filmes desde o momento em que foi convidado pelos amigos a realizar a primeira produção neste grupo. Sua responsabilidade concentra-se em articular o grupo a produzir, reunir atores, produzir roteiros, conseguir locações, contatar com músicos, figurinistas, diretores de arte etc. Apresenta-se como figura que está no centro de todos os atores e equipe técnica articulando-os com o objetivo de fazer cinema em coletivo. Por isso, ocupa-se em estar no meio das relações, articulando-as. Ao invés de estar em outro patamar, observando e dirigindo o grupo à distância, ele parece interessar-se por agregar uns aos outros pelo prazer de fazer cinema junto.

Outro ponto que observamos é o processo de integração de novatos ao grupo: acontece muito mais a partir da sua disponibilidade em agir em comum. Explicamos: durante as gravações das cenas, vimos diletantes que visitavam despretensiosamente o estúdio ou as locações e, que, ao final do dia, já tinham se maquiado, vestido e atuado. Assim, o método do Sistema CooperAÇÃO vai incorporando quem se aproxima, ou seja, quem visita o set de filmagem, pode agir, atuar de algum modo, sendo convidado a cooperar também. Por isso, é um método aberto de agremiação e cooperação. Sobre isso, Muniz (2013b) responde

- Muniz, você me disse que quando seus amigos te chamaram para fazer o primeiro filme você propôs fazê-lo em cooperação, de onde você tirou esta idéia de fazer junto, o que te motivou a isso? 
- Porque eu não podia pagar eles (sic.), um câmera hoje ganha cinco mil reais em uma filmagem, um iluminador ganha tanto, e assim por diante, um maquinista ganha tanto e nosso filme tem o salário alto, nosso filme é o mais caro do Estado de Goiás, porque eu pego os melhores profissionais do Estado de Goiás, só que eu não pago eles e eles não me pagam, cada um fica com a cópia do filme como uma vitrine nossa, do nosso trabalho. Então quando eu tive esta idéia da cooperativa foi porque eu sabia que muita gente tinha vontade de mostrar as coisas que sabia, mas não tinha espaço em Goiás, como não tem. Toda cidade é feita de panela. Pode notar em Goiânia e Goiás que tem uma panela do teatro e tem outro grupo que está fora da panela que eles recusam e dão cotoveladas constantes nos que estão fora da panela deles. A mesma coisa é no cinema, tem um grupo de cinema em Goiânia, que nós sabemos quem é que é muito zoiudo (sic.), eles fazem as produções deles e são as mesmas pessoas e nunca deixa outro grupo que não está ligado a eles entrar então nós tinha (sic.) necessidade de fazer também um grupo nosso. Só que esse grupo ficou aberto para quem quiser, ele não ficou fechado como os outros grupos que são fechados, e tem feito vários trabalhos por isso. Está com uns quinze filmes já feitos. E com dois roteiros bolados já, fazer mais dois e vamos fazendo, enquanto tiver força vamos fazendo.

\section{Considerações}

Argumentamos que o Sistema CooperAÇÃO - Amigos do Cinema se comporta mais como um coletivo artístico contemporâneo, dada a sua efemeridade e contínua formação grupal, do que como uma cooperativa de atores e técnicos realizadores de filmes. Assim, apresentamos que o método cooperação, neste agrupamento, resulta na reciprocidade das ações, ligando-se diretamente ao equilíbrio de regras construídas em conjunto, em oposição às coações. Desse modo, podemos afirmar que, dentro do grupo, a distribuição das tarefas não se encerra na especialidade ou na expertise de cada membro. Como o grupo produz pela via da diversão e do voluntariado, seus membros não se envolveram, até hoje, com as produções apenas pelo cachê, nem foram escolhidos exclusivamente pela competência individual.

Obviamente, o resultado estético das realizações refletem estas escolhas, o que implica em serem elas constituintes do estilo fílmico do Sistema CooperAÇÃO. Desse modo, percebemos que tão importante quanto produzir filmes em Goiás, 
no interior do Brasil, em condições adversas e à margem dos grupos locais, é produzi-lo em um coletivo que coopera entre si. Desse modo, a via da produção independente faz sentido se, e somente se, em um conjunto aberto ao método CooperAÇÃO. Assim o método de realizar filmes deste coletivo é a CooperAÇÃO, que se fundamenta no voluntariado, na ausência do cachê que suprime certa obrigatoriedade, pois não apresenta uma moeda de troca além do prazer de estar ali para se divertir como Amigos do Cinema.

Ao mesmo tempo o voluntariado gera imprevistos garante o sentido do método CooperAÇÃO: que é a autonomia dos atores e a reciprocidade das relações. Assim, argumentamos que as realizações deste coletivo artístico precisam ser consideradas à luz do seu método, ou seja, a CooperAÇÃO que põe em risco a continuidade da realização, a coerência e o continuísmo da narrativa, mas é ela mesma a estética da autonomia e da solidariedade que o grupo interessa-se por vivenciar.

\section{NOTAS}

1. Conferir títulos em filmografia.

2. Todas as traduções presentes nesta reflexão são livres.

3. FREE URBANA - Public Phenomena.

4. Public Phenomena - Informal Modifications of Shared Spaces.

5. Histórico Coro Coletivo.

\section{Referências}

CRUSCO, Sérgio. A vida em um coletivo. Maire Claire, São Paulo, n. 273, p. 94-104, dez.2013.

FREEURBANA-PublicPhenomena. Disponívelem:<http://www. flickr.com/photos/15564781@No4/sets/72157602574603077/ with/1783067400/>. Acesso em: 27. jan. 2014.

Histórico do Coro Coletivo. Disponível em: $<$ http://corocoletivo.org/historico-de-formacao-do-coro/>. Acesso em: 10.jan.2014.

HOLLANDA, Heloisa Buarque de. Coletivos. (Artigo publicado em 10.set.2013).Disponível em: < http://www.heloisabuarquedehollanda.com.br/coletivos/>. Acesso em: o6.jan.2014.

MESQUITA, A. L. Insurgências poéticas: arte ativista e ação coletiva (1990-200o). São Paulo, 2008. 429 p. Dissertação (Mestrado em História). Departamento de História da Uni- 
versidade de São Paulo.

MUNIZ, Martins. Entrevista concedida a Lara Lima Satler. Goiânia. 24.fev.2013a.

. Entrevista concedida a Lara Lima Satler. Goiânia. 13.nov.2013b.

PAIM, Claudia. Táticas de artistas na América Latina: coletivos, iniciativas coletivas e espaços autogestionados. Porto Alegre: Panorama Crítica Ed, 2012. 200 p.

- Coletivos, iniciativas coletivas: modos de fazer na América Latina contemporânea. Porto Alegre, 2009. 294 p. Tese (Doutorado em Artes Visuais). Instituto de Artes, Universidade Federal do Rio Grande do Sul.

PIAGET, Jean. Estudos Sociológicos. Rio de Janeiro: Forense, 1973. $234 \mathrm{p}$.

1998. $262 \mathrm{p}$.

Sobre a pedagogia. São Paulo: Casa do Psicólogo,

Public Phenomena - Informal Modifications of Shared Spaces.

Disponível em:< http://www.temporaryservices.org/public_phenomena.pdf>. Acesso em: 27. jan. 2014.

SENNETT, Richard. $O$ artífice. Rio de Janeiro: Record, 2012. $360 \mathrm{p}$.

Site Specific. Enciclopédia Itaú Cultural de Artes Visuais (Verbete atualizado em 04.nov.2010). Disponível em: <http:// www.itaucultural.org.br/aplicExternas/enciclopedia_IC/ index.cfm?fuseaction=termos_texto\&cd_verbete $=5419>$. Acesso em: 11.jan.2014.

STIMSON, Blake; SHOLETTE, Gregory (Editors). Collectism After Modernism: The Art of Social Imagination After 1945. Minneapolis, London: University of Minnesota Press, 2007. $312 \mathrm{p}$.

\section{Filmografia do Sistema CooperAÇÃ̃ - Amigos do Cinema}

O CAPITÃO do Mato. Direção: Martins Muniz. Realização: Sistema CooperAÇÃO Amigos do Cinema. Duração: 50 min. Brasil. 2013.

FORA de padrão: o filme. Direção: Martins Muniz. Realização: Sistema CooperAÇÃO Amigos do Cinema. Duração: 40 min. Brasil. 2012.

GARROTE, No. Direção: Martins Muniz. Realização: Sistema CooperAÇÃO Amigos do Cinema. Duração: 45 min. Brasil. 2010.

PÉ de pano, O. Direção: Martins Muniz. Realização: Sistema CooperAção Amigos do Cinema. Duração: 26 min. Brasil. 2011. 
MATUTO, O - ou Dois dias e meio. Direção: Martins Muniz. Realização: Sistema CooperAÇÃO Amigos do Cinema. Duração: $56 \mathrm{~min}$. Brasil (sem referência do ano).

MEDALHÃO e a fé, O. Direção: Martins Muniz. Realização: Sistema CooperAÇÃO Amigos do Cinema. Duração: 45 min. Brasil (sem referência do ano).

PEDRO Ludovico: herói ou vilão. Direção: Martins Muniz. Realização: Sistema CooperAÇÃO Amigos do Cinema. Duração: 60 min. Brasil (sem referência do ano).

SUVACO de cobra. Direção: Martins Muniz. Realização: Sistema CooperAÇÃO Amigos do Cinema. Duração: 35 min. Brasil (sem referência do ano).

FRAGMENTOS. Direção: Martins Muniz. Realização: Sistema CooperAÇÃO Amigos do Cinema. Duração: (sem referência de duração). Brasil (sem referência do ano).

LIGAÇÃO, A. Direção: Martins Muniz. Realização: Sistema CooperAÇÃO Amigos do Cinema. Duração: (sem referência de duração). Brasil (sem referência do ano).

SUPER Homem, O. Direção: Martins Muniz. Realização: Sistema CooperAÇÃO Amigos do Cinema. Duração: (sem referência de duração). Brasil (sem referência do ano).

DIABO Velho, o Anhanguera. Direção: Martins Muniz. Realização: Sistema CooperAÇÃO Amigos do Cinema. Duração: (sem referência de duração). Brasil (sem referência do ano).

CACHORRO Louco. Direção: Martins Muniz. Realização: Sistema CooperAÇÃO Amigos do Cinema. Duração: (sem referência de duração). Brasil (sem referência do ano).

LONA Preta. Direção: Martins Muniz. Realização: Sistema CooperAÇÃO Amigos do Cinema. Duração: (sem referência de duração). Brasil (sem referência do ano).

LENDA do Milho, A. Direção: Martins Muniz. Realização: Sistema CooperAÇÃO Amigos do Cinema. Duração: (sem referência de duração). Brasil. 1999.

Recebido em: 20/10/14

Aceito em: 10/11/14 


\section{LARA LIMA SATLER \\ satlerlara@gmail.com}

Doutoranda em Arte e Cultura Visual (FAV/UFG). Professora na

Universidade Federal de Goiás (UFG), na Faculdade de Comunicação e Informação (FIC), onde ministra as disciplinas Teorias da Imagem I e II e participa do grupo de pesquisa Cultura Visual e Educação (PPCACV/ FAV/UFG/ Cnpq).

\section{ALICE FÁTIMA MARTINS \\ profalice2fm@gmail.com}

Pós-Doutora em Estudos Culturais (PACC/UFRJ), doutora em Sociologia (UnB). Professora na Faculdade de Artes Visuais (FAV/ UFG), curso de Licenciatura em Artes Visuais e no PPG em Arte e Cultura Visual. Autora dos livros Catadores de Sucata da Indústria Cultural, pela Editora da UFG (2013) e Saudades do Futuro: a ficção científica no cinema e o imaginário social sobre o devir, pela Editora da UnB (2013). 